\title{
Nanotechnology STEM Program via Research Experience for High School Teachers
}

\author{
Mangilal Agarwal, ${ }^{1, *}$, Qurat-ul-Ann Mirza ${ }^{3,7}$, Joseph Bondi ${ }^{3,7}$, Brandon Sorge ${ }^{3}$, Maher Rizkalla ${ }^{1,4}$, Richard \\ Ward $^{2}$, Corbin Feldhaus ${ }^{5}$, Amy Hinshaw ${ }^{6}$, and Kody Varahramyan ${ }^{1,4}$ \\ ${ }^{1}$ Integrated Nanosystems Development Institute (INDI) \\ ${ }^{2}$ Center for Research and Learning \\ ${ }^{3}$ STEM Education and Research Institute (SERI) \\ ${ }^{4}$ Department of Electrical and Computer Engineering, Indiana University-Purdue University Indianapolis \\ ${ }^{5}$ Charlestown High School, Charlestown, Indiana \\ ${ }^{6} \mathrm{McKenzie}$ Center for Innovation \& Technology, Indianapolis \\ ${ }^{7}$ Purdue School of Science, Indiana University-Purdue University Indianapolis
}

\begin{abstract}
In this work, we report the outcomes from the IUPUI STEM outreach program "STEMCorp" that inspires high school students to pursue STEM majors. The STEMCorp program was modeled after the Multidisciplinary Undergraduate Research Initiative (MURI) at IUPUI. MURI research program introduces undergraduate students from at least two different departments with mentors from different disciplines to address research issues that may compose both engineering and sciences. The STEMCorp program brings undergraduate students to work with faculty and high school teachers to create a positive impact in enriching the high school students by introducing them to engineering and science with emphasis on nanotechnology for future careers. The program describes the collaborative activities between faculty, undergraduate students and high school STEM teachers in the creation of project-based, studentcentered learning modules in the field of nanotechnology. The paper details the activities of the STEMCorp participants including their experiences in developing working partnerships and creating and implementing learning modules in the designated high school courses. The success of the program is assessed by the measurable outcomes of high school students' research projects. Specifically, two different learning modules are presented, including the processes used in the development of these modules and their outcomes. The collaborative research
\end{abstract}

Submitted on April 27th, 2015. The authors are with the Schools of Engineering \& Technology and Science at Indiana University-Purdue University Indianapolis.

Dr. Mangilal Agarwal is a Associate Director for Research Development and Director of Integrated Nanosystems Development Institute (INDI) at IUPUI, 755 W Michigan St. Indianapolis, IN 46202 USA (*Corresponding Author: agarwal@iupui.edu)

Ms. Qurat-ul-Ann Mirza and Mr. Joseph Bondi are undergraduate students in the School of Science at IUPUI.

Dr. Brandon Sorge is a Research Associate at the STEM Education Research Institute at IUPUI.

Dr. Maher Rizkalla is a Professor \& Associate Chair of Department of Electrical and Computer Engineering and Member of Integrated Nanosystems Development Institute (INDI) at IUPUI.

Dr. Richard Ward is a Professor of Anthropology and Dentistry Faculty of University College

Mr. Feldhaus is a High School Teacher at Irvington Public School, Teaches Biology and Human Genetics.

Ms. Amy Hinshaw is a High School Teacher at the Health and Biomedical Sciences, Metropolitan School District of Lawrence Township.

Dr. Kody Varahramyan is a Professor of Electrical and Computer Engineering at IUPUI. discussions between the faculty, undergraduate students, and high school teachers are detailed, covering research methodologies, hypothesis, and expected outcomes.

Index Terms-STEM, nanotechnology, research experience for teachers, high school students, projects, collaboration

\section{INTRODUCTION}

$\mathrm{M}$ URI is a research program that was established at IUPUI more than 10 years ago. It was created to encourage multidisciplinary projects from across schools [1,2]. Projects offered by mentors from different disciplines have led to unique research experiences for undergraduate students. More than 40 students are funded every semester from this program. The projects are analogous to industrial models where different engineers and scientists work together on a multidisciplinary project. One example of such a collaborative project is a battery system, where electrical engineers contribute to the electrical and mathematical models while mechanical engineers contribute to the thermal science issues within the system. Chemical engineers, however, are also experts in the electrochemical process of the system. Control engineering and computer engineering may add to the optimization and safety of the devices. Likewise, in many medical research projects, students from biology, bioengineering, computer engineering, image processing, among many others, may contribute to such multidisciplinary research. These programs operate with the same ideology; using information and skillsets from various disciplines to achieve a common goal. This approach can provide more rounded and comprehensive solutions to modern day problems.

It has been widely acknowledged that there is a need to improve students' STEM skills and increase diversity in STEM fields at all levels of education [3-6]. A necessary step in addressing this need is drawing students to STEM disciplines at an early age thereby assuring that they have developed necessary skill sets for college degrees in STEM fields. For this, based on the MURI model, a pilot project, 
"STEMCorp," was designed to form collaboration among high school teachers from urban schools, IUPUI students who have been successful in STEM fields, and IUPUI faculty who have demonstrated interest in improving STEM education. The project also builds on IUPUI's existing strengths in nanotechnology outreach and education through the Integrated Nanosystems Development Institute (INDI) [7]. INDI provides a good infrastructure for student-mentor interactions, which was utilized because nanotechnology has proven to be a STEM subject attractive to high school students. More specifically, the project builds on the success of the already established INDI nanotechnology camps for high school teachers and students that were established four years ago [8]. The need for a better means of transferring the content and the skills from these camps into classrooms has been identified by high school teachers who have taken part in assessments at the end of the camp sessions. The STEMCorp collaborative research team addresses these concerns as research questions and provides solutions that relate to this gap in transference.

The STEMCorp program is developed and administered in collaboration between the following three IUPUI campus units:

\section{The Center for Research and Learning (CRL) [9]}

This center is associated with the Office of the Vice Chancellor for Research. CRL is dedicated to serving students through a series of undergraduate research programs overseen by CRL program leaders. These programs offer students the opportunity to carry out innovative research, scholarship, and creative activity with faculty mentors through internally and externally funded programs. CRL programs expose and engage students in research experiences, providing effective pathways for lifelong active learning, scholarship, and professional development. The vision of CRL is to create and sustain world class programs in inquiry-based student learning through innovative multidisciplinary collaboration and effective mentoring, and promote lifelong active learning and professional development.

\section{A. The STEM Education Research Institute (SERI) [10]}

SERI is dedicated to education research in STEM fields, combining knowledge of teaching and learning with deep knowledge of discipline-specific science content. Based on this, the institute is dedicated to the development and dissemination of STEM education programs in collaboration with external partners. The vision of SERI is to be a nationally and internationally recognized center of excellence for STEM education research, contributing to the advancement of STEM education in Indiana and the nation.

\section{B. The Integrated Nanosystems Development Institute (INDI)}

INDI is a research center comprised of faculty from the Schools of Science, Engineering and Technology, and Medicine. The given faculty have expertise in a wide range of fields, including chemistry, physics, biology, material science, electrical and computer engineering, mechanical engineering, orthopedics, pathology and laboratory medicine. The vision of INDI is to be a resource for the realization of nanotechnology-based miniaturized systems that contribute to the economic growth and social advancement of Indiana and the nation and benefit humanity as a whole.

\section{STEMCORP}

For STEMCorp, the project was divided into four distinct phases.

\section{A. Phase I}

Three high school science teachers from the Indianapolis area were recruited, three IUPUI faculty in STEM disciplines were identified (one from science, one from engineering, and one from education), and six undergraduate students (STEMCorp scholars) in STEM fields were recruited who served as the research scholars in the summer and as high school teaching assistants and peer mentors in the academic year.

\section{B. Phase II}

The STEMCorp scholars participated in three weeks of INDI's nanotechnology camp activities, including the sessions for high school students and high school teachers. In addition, the scholars participated in the CRL's summer undergraduate research program and attended a series of research and professional development workshops designed to enhance their research skills. The STEMCorp Scholars also obtained documentation required to engage in human subject research and to work with minors. At the end of Phase II, the team delivered the following:

1) Initial needs assessment data

2) A set of activities that can be used in high school classrooms to further nanotechnology-related skills

3) Guidelines for the facilitation of these activities

4) A prototype for a mobile kit that contains the materials needed to implement these activities

5) A set of online resources (web quests, videos, interactive games, etc. that can be used to further enhance students' skills)

6) A schedule for piloting the activities in the classrooms during the following academic year.

\section{Phase III}

The research team implemented the activities with the high school students. The high school teachers took the lead and IUPUI STEMCorp scholars assisted the teachers. The Program Coordinator, IUPUI faculty, and the high school teachers all served as mentors for the IUPUI STEMCorp scholars.

\section{Phase IV}

Finally, in Phase IV, the STEMCorp team will reassemble to assess outcomes and write a final report on the results. Deliverables for this phase of the project will be 
1) research abstracts, posters, and papers from the STEMCorp student scholars

2) final reports from the IUPUI faculty mentors, high school teachers, and the program coordinator

3) needs assessment data and program evaluation outcomes gathered by the two SPEA students

4) presentation of results at one conference at a minimum

5) development of options for sustaining the STEMCorp program

Both formative and summative assessment methods are being employed including surveys, interviews, focus groups, and analysis of research products (teaching modules). The inputs from these assessment methods will be used to reflect and to enhance the program. In continuation of Phase IV, participants will review and evaluate their individual experiences of their first summer and academic year participation in the program, as part of their work. Reporting of the student experiences will take place through participation in the CRL's summer poster symposium, the IUPUI Research Day symposium, and/or the Indiana University Undergraduate Research Conference. Phase IV will also include collaborative work by the "community of practice" with the product of a summary "white paper" reviewing outcomes of the assessments and evaluations. In addition, the white paper will identify the elements associated with successful completion of STEM coursework and make recommendations for sustaining the program.

\section{OUTCOMES}

\section{A. Short-term Outcomes}

1) Indicators identified for competence in nanotechnologyrelated knowledge and skills mapped to high school standards.

2) Collaboration among faculty from IUPUI Schools of Science, Engineering \& Technology, and Education; high school science teachers interested in integrating nanotechnology-related content and skills into their high school curricula; and IUPUI STEM majors interested in research and nanotechnology.

3) Increased knowledge and skills related to nanotechnology among IUPUI faculty, high school teachers, IUPUI STEM majors, and the approximately 200 high school students from schools represented by teachers in the program.

4) Increased research, mentoring, and professional development skills for IUPUI STEM majors.

5) Materials and resources related to nanotechnology skills identified and links placed on INDA and SERI websites for use by other community schools.

6) Hands-on mobile nanotechnology teaching kits developed for use by CRL scholars and high school teachers in the field.

B. Long-term Outcomes

1) Changes to high school curricula to integrate nanotechnology knowledge and skills.
2) Increased number of participating high school students selecting STEM majors in college (especially those related to nanotechnology).

3) Increased number of participating high school students selecting IUPUI as their college of choice.

1) Increased number of CRL scholars going on to graduate school in STEM-related fields (especially those related to nanotechnology).

\section{RESULTS AND DISCUSSIONS}

Two teaching modules have been developed under STEMCorp so far.

\section{A. Example Project 1}

Project 1 was conducted by high school students at local career and technical center. The students involved were high school juniors or seniors in their third-year of the Project Lead the Way Biomedical Science curriculum. In the first semester, students designed a lab to compare the antimicrobial effects of silver nanoparticles, silver ions, and traditional antibiotics on the growth of multi-drug resistant bacteria. Most students compared the zone of inhibition created by the different potential antibiotics. Students wrote lab reports describing their findings.

In the second semester, student groups researched ways to use nanotechnology for the early detection of cancer and presented their findings. Students created 3-D models demonstrating how the device works, image 1.

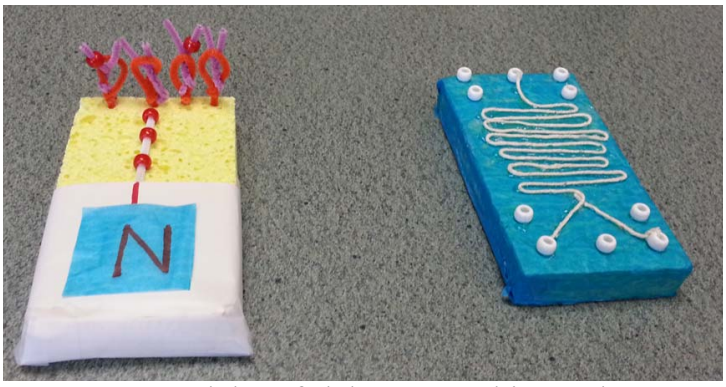

Image 1: 3-D models of lab on a chip and nose sensor constructed by students at McKenzie Career Center using simple school supplies.

Students were given a pre-test and post-test $(\mathrm{N}=76)$. To measure the change in their knowledge of nanotechnology, nanotechnology devices and their usage in cancer detections. The questions include:

1. Which of the following is/ are nanoscale objects?

a) An antibody.

b) A hydrogen atom

c) A strand of DNA.

d) A cancer cell

2. Elaborate on the nanotechnology processes for detecting cancer?

3. Much research is devoted to developing better methods for diagnosing cancer. Describe TWO of the problems or limitations of the current cancer diagnostic methods/tools. 
4. List TWO types of nanotechnologies or nanomaterials used in the detection of cancer.

\section{Explain how ONE developing nanotechnology for cancer} detection works.
a) Include as many details of the process as you are able.
b) Be sure to discuss why this is a NANO-technology.
c) What is NANO about it?

\section{Describe ONE advantage that nanotechnology devices/ materials have over our traditional methods of diagnosing cancer.}

These questions were assigned point values. The first two questions were worth one point each, questions three through six required detailed description and thus were assigned multiple points.

For the pre-test, the majority of students from the class responded "I don't know" to the above set of questions. After the activity, they were given a post-test which was identical to the pre-test. The questions were designed to test their knowledge of nanotechnology processes, current research in cancer diagnosis using nanotechnology and advantages in nanotechnology devices that may have over traditional methods of cancer diagnosis.

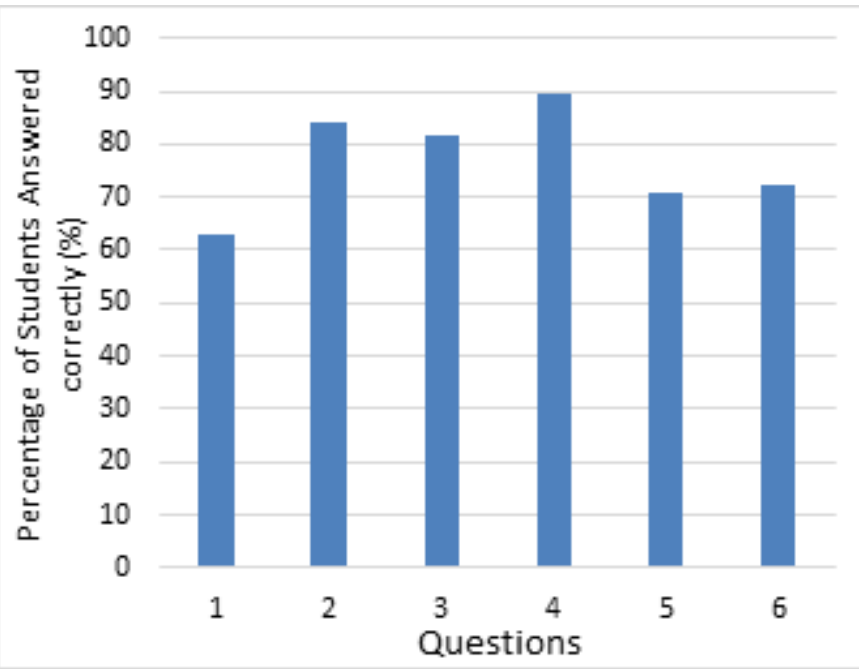

Figure-3: Shows the percentage of students that answered correctly. 68-out-of-76 students, $89.5 \%$, provided two nanotechnologies or nano-materials that are used in cancer detection.

Scores from all 76 students were averaged to $86 \%$. Students scored high on questions relating to cancer detection (Figure3) However, students struggled with identifying the three nano-scale objects, and only 48 students answered it correctly.

Overall, student response was highly positive and their feedback with the module was encouraging.

\section{B. Example Project 2}

This project is a two week long Project Based Learning Unit (PBLU) that focuses on creating a model of a renewable energy source that is best suited to produce energy at the local Charlestown state park. Students picked their own groups based on group roles, collaborated in their group, fulfilled their specific group roles, and presented to a professional audience as a cohesive group.

The four group roles were Project Coordinator, Scientist, Engineer, and Nanotechnology Specialist. The Project Coordinator updated the teacher, twice a week, on how the group was doing, helped other students with their tasks, and was responsible for any work of absent students. The Scientist collected data for a renewable energy source assessment, created arguments for the best type of renewable energy source based on data, and did research on renewable energy sources to pick the best possible one. The Engineer used a 3D printer to create a working model of a renewable energy source and did research on renewable energy source structures. Finally, the Nanotechnology specialist explained how nanotechnology is used in this field, turned in a presentation on how nanotechnology can affect renewable energy technology, and researched renewable energy sources.

Each member also presented their group's final product. Some interesting points of the project are: 1) students collected real world data on light intensity, water speed, wind speed, and biomass at Charlestown State Park. From this, the students decided on the best renewable energy source (solar, hydroelectric, wind energy, or biomass) based on the collected data; 2) students created a dye-sensitized solar cell; 3) students created a 3D working model of energy technology using a 3D printer. All of the groups operated by using one or more of the following: 1) identification of specific relevant group roles decided on by group members, 2) creation of a group contract to make group norms and ways to deal with in-group problems; 3) presentation to professionals in the field during a gallery walk, and 4) reflections on project outcomes and group and individual performances. This last piece is especially important because it builds metacognitive skills the students will need to self-evaluate.

This project was developed to help students realize the importance of renewable energy sources, introduce them to nanotechnology, demonstrate how nanotechnology is used in many renewable energy sources, express how nanotechnology is becoming more relevant in modern science, technology, and medicine, and expose them to how collaborative projects are conceived, implemented, and given exposure in the real world. The goal was to build the necessary skills among students to teach self-reflection, constructive feedback norms, presentation skills, constructive problem solving skills, and to give the students a better grasp on how scientific inquiry is implemented in the real world.

Participating students $(\mathrm{N}=39)$ were given a pre- and postassessment that consisted of multiple choice questions to gauge the student's basic understanding of general 
nanotechnology and renewable energy concepts; fill in the blank questions to test a student's understanding of the integration of nanoscale processes in renewable energy sources; and open ended questions to gauge a student's understanding of what nanotechnology actually is. Between taking the pre-assessment and post-assessment, students created dye-sensitized solar cells and were taught on how nanotechnology plays a role in solar cells. The students were also given a basic introduction to what nanotechnology is and other applications of how nanotechnology is used in modern technology.

The students showed a $49.7 \%$ increase in individual score on the post-assessment when compared to the pre-assessment. Students showed a $28.4 \%$ increase in their general nanotechnology and renewable energy understanding and a $73.2 \%$ increase in their understanding of lab-specific questions. Open ended questions from the pre-assessment showed that the students did not have a good understanding of nanotechnology. The post-assessment indicated that the students gained a basic understanding of nanotechnology and would still like to learn more about nanotechnology and how it can be integrated into modern technology. From the assessment, the students showed a base understanding of the integration of nanotechnology in solar cells, however many students were interested in learning other applications. From this, it can be inferred that by proving an introduction of nanotechnology to high school students their interest will increase and they will possibly do further research. To help facilitate this, students can be provided with other examples of nanotechnology integration and given sources for independent research.

\section{CONCLUSION}

The two projects conducted at high schools covering healthcare and renewable energy projects indicate the success of the STEMCorp activities. These two projects served as a pilot study where the STEMCorp, faculty, high school teachers, and undergraduate students have all participated in the initiation of these projects. These projects showed success, however, some aspects of each project would have helped them develop much quicker. Early coordination between the advisors, students, and teachers would have led to quicker success of this program. Nonetheless, once there was proper coordination, there was a great impact among the students. By sending a student from STEMCorp to the high schools, students showed more interest in learning about nanotechnology and other STEM related subjects. The collaborative work between the various units from INDI, STEMCorp, SERI, CRL, and University faculty have led to the success of this program. The outcomes of these activities have enhanced the students' understanding of nanotechnology. By introducing students to the research in nanotechnology, they are aware of modern applications of nanotechnology in energy and medicine and hence, understand possible careers in nanoscience.

\section{ACKNOWLEDGEMENT}

The authors would like to acknowledge the Venture Fund from the Solution Center at IUPUI and the Indiana Space Grant Consortium (INSGC) award through Purdue University. The experiences from STEMCorp and IUPUI Nanotechnology Discovery Academy (INDA) also led to a Research Experience for Teachers award (\#1406995) from the National Science Foundation. The authors also appreciate the efforts of Mr. Vinay Kumar Suryadevara for his assistance with the formatting of this manuscript.

\section{REFERENCES}

[1] Indiana University-Purdue University Indianapolis. (2015, 4/27/2015). Center for Research and Learning: Multidisciplinary Undergraduate Research Institute (MURI).

[2] M. Rubin, et al., "A Multidisciplinary Collaborative Model Project Emphasizing Elements from Electrical Engineering, Mechanical Engineering, and Science Majors," in American Society for Engineering Education, 2009.

[3] Hedges LV, A Nowell (1999) Changes in the black-white gap in achievement test scores. Sociology of Education 72: 111-135.

[4] Education Week (2003) If I can't learn from you: ensuring a highly qualified teacher for every classroom. Edwards VB (ed), Washington, DC, Quality Counts, 22(17): 1-153.

[5] Center for Evaluation \& Education Policy (2009, Fall) An analysis of recent national reports as they relate to Indiana: high school dropout and completion rates in the United States: 2007. Indiana University, Bloomington, IN, Focus on Indiana 3(3): 1-4. Accessed 9/24/2013, from CEEP http://ceep.indiana.edu/projects/PDF/FOI_V3N3_2009.pdf. webpage:

[6] National Center for Education Statistics (2011) Mathematics 2011: national assessment of educational progress at grades 4 and 8 (NCES 2012-458). Institute of Education Sciences, U.S. Department of Educations, Washington, DC, The Nation's Report Card, Full Report: 195. Accessed 08/31/2013, from NCES webpage: http://nces.ed.gov/nationsreportcard/pdf/main2011/2012458.pdf.

[7] Indiana University-Purdue University Indianapolis. (2015, 4/27/2015). INDI Integrated Nanosystems Development Institute. Available: indi.iupui.edu

[8] Indiana University-Purdue University Indianapolis. (2015, 4/27/2015). Center for Research and Learning - IUPUI Nanotechnology Discovery Academy.

Available: http://crl.iupui.edu/programs/INDA/nanotechnologyForStudents.asp

[9] Indiana University-Purdue University Indianapolis. (2015, 4/27/2015). Undergraduate Research at IUPUI - Center for Research and Learning. Available: http://crl.iupui.edu/

[10] Indiana University-Purdue University Indianapolis. (2015, 4/27/2015). SERI: STEM Education Research Institute. Available: http://seri.iupui.edu/ 